\title{
CONHECIMENTO E PRÁTICA DE ACADÊMICOS DE ENFERMAGEM SOBRE CUIDADOS COM PORTADORES DE FERIDAS
}

\author{
Knowledge and practice of nursing students about caring for patients with wounds \\ Conocimiento y práctica de estudiantes de enfermería sobre el cuidado de los \\ pacientes con heridas
}

\author{
Adriano Menis Ferreira ${ }^{1}$ \\ Dioner da Silva Paula ${ }^{4}$
}

\author{
Marcelo Alessandro Rigotti \\ lara Barbosa Ramos ${ }^{5}$
}

\author{
Silvana Barbosa Pena ${ }^{3}$ \\ Vanessa Damiana Menis Sasaki ${ }^{6}$
}

\section{RESUMO}

0 presente estudo teve como objetivo identificar o conhecimento, a prática e fontes de informações de graduandos de enfermagem sobre o cuidado a por tadores de feridas. Trata-se de estudo quantitativo com delineamento descritivo-exploratório realizado com 68 graduandos de enfermagem do $9^{\circ}$ período de uma Universidade Pública do estado de Mato Grosso do Sul. A coleta foi realizada com duas turmas nos anos de 2008 e 2009. Os dados foram coletados por um questionário adaptado e validado. Somente 6 $(54,5 \%)$ itens alcançaram acertos acima de 50\%. Desses, 4 (36,3\%) não chegaram a $70 \%$ de acertos. Apenas $2(11,1 \%)$ itens foram respondidos corretamente por todos os acadêmicos. Constatou-se que a maioria dos acadêmicos não utiliza fontes de informações para atualização sobre 0 assunto. Os resultados demonstraram que o nível de conhecimento sobre o cuidado a portadores de feridas é baixo e, portanto, investimentos no ensino de graduação do referido curso são necessários.

Palavras-chave: Cuidados de enfermagem. Avaliação. Cicatrização de feridas. Estudos transversais.

\begin{abstract}
The present cross-sectional study aimed to identify the knowledge, practice and sources of information of undergraduate nursing students in care to wounds. Participants were 68 undergraduate nursing students in their $9^{\text {th }}$ period at a Public University in Mato Grosso do Sul State, Brazil. Data were collected from two classes in 2008 and 2009. An instrument, with items on wound handling, was adapted and validated for data collection. Only six $(54,5 \%)$ items had more than $50 \%$ of correct answers. From these, $4(36.3 \%)$ did not reach $70 \%$ correct answers, however, the rate did not reach $70 \%$. Only two $(11.1 \%)$ items were correctly answered by all students. It was evidenced that most students do not use sources of information for updating on the topic. Results showed that the level of knowledge, concerning care to wounds, is low, thus evidencing the need of investments in undergraduate teaching in the mentioned university program.
\end{abstract}

Keywords: Nursing Care. Evaluation. Wound Healing. Crossseccional estudies.

\section{Resumen}

Este estudio transversal objetivó identificar el conocimiento, la práctica y las fuentes de informaciones de estudiantes graduandos de enfermería sobre el cuidado con heridas. Participaron 68 estudiantes del noveno período de una Universidad Pública en el Estado de Mato Grosso do Sul, Brasil. Los datos fueron recolectados de dos clases en los años de 2008 y 2009. Un instrumento con ítems acerca del manejo de heridas fue adaptado y validado para la recolecta de las informaciones. Solo 6 (54,5\%) ítems tuvieron aciertos de más del $50 \%$. De ellos, cuatro $(36,3 \%)$ no alcanzan el $70 \%$ de respuestas correctas. Sólo $2(11,1 \%)$ ítems fueron respondidos correctamente por todos los estudiantes. La mayoría de Estudiantes no utiliza fuentes de información para actualización sobre el tema. Los resultados demostraron que el nivel de conocimiento acerca del cuidado con heridas es bajo y, por lo tanto, inversiones en la enseñanza de la graduación del referido curso son necesarias.

Palavras-chaves: Atención de Enfermería. Evaluación. Cicatrización de Heridas. Estudios Transversales.

\footnotetext{
'Enfermeiro. Professor Doutor do Curso de Enfermagem da Universidade Federal de Mato Grosso do Sul -Três Lagoas/MS. Pós-doutor em Enfermagem pela EERPUSP. Orientador do Programa de Mestrado em Saúde e Desenvolvimento na Região Centro-oeste e Mestrado em Enfermagem da UFMS. Campo Grande-MS. Brasil. E-mail: a.amr@ig.com.br; 'Enfermeiro Licenciado. Mestre em Ciências pelo Programa de Enfermagem Fundamental da Escola de Enfermagem de Ribeirão Preto da Universidade de São Paulo - Ribeirão Preto-SP. Brasil. Professor Assistente do Curso de Enfermagem da Universidade Federal de Mato Grosso do Sul -Coxim/MS E-mail:marcelosaude@hotmail.com ; ${ }^{3}$ Enfermeira. Mestre em Enfermagem. Especialista em Enfermagem Dermatológica. Professora Assistente do Curso de Enfermagem da Universidade Federal de Mato Grosso do Sul -Três Lagoas-MS. Brasil. E-mail: silpena@terra.com.br; ${ }^{4}$ Enfermeiro. Licenciado. Enfermeiro Assistencial do Hospital Nossa Senhora Auxiliadora Três Lagoas-MS. Brasil. E-mail: dioner_enf@hotmail.com; ${ }^{5}$ Enfermeira. Servidora da Prefeitura Municipal de Campo Grande/MS. Especialista em Saúde Pública e Saúde da Familia. Mestranda pelo Programa em Saúdee Desenvolvimento na RegiãoCentro-oeste daUniversidadeFederal de Mato Grosso doSul.Campo Grande-MS. Brasil. E-mail:enfiararamos@gmail.com;;Enfermeira. Estomaterapeuta. Mestranda em Ciências pelo Programa de Enfermagem Fundamental da Escola de Enfermagem de Ribeirão Preto da Universidade de São Paulo - Ribeirão Preto-SP. Brasil. E-mail: vanessasasaki@hotmail.com
} 


\section{INTRODUÇÃO}

Cuidar das pessoas com feridas faz parte da assistência de enfermagem ${ }^{1}$. Com os avanços tecnológicos nesta área, obtiveram-se novos produtos e métodos utilizados no cuidar desses pacientes. Quanto aos enfermeiros, surgiu a necessidade da busca por um melhor preparo técnico-científico para o adequado atendimento dessa clientela, que vai ao encontro a esses novos avanços ${ }^{1,2}$. A enfermagem sempre esteve inserida no papel de principal cuidador de pessoas com feridas desde seu surgimento como profissão ${ }^{3}$.

Pesquisas sobre prevenção e tratamento de feridas são referidas em publicações de enfermagem ${ }^{1-6}$, demonstrando o importante papel e responsabilidade do enfermeiro nesse processo, cabendo a esse profissional, dentre outros aspectos, avaliar a lesão e prescrever 0 cuidado mais adequado, além de orientar e supervisionar a equipe de enfermagem na execução do curativo ${ }^{1}$. Portanto, é necessário que o enfermeiro perceba que essas competências são intrínsecas ao seu cotidiano. Entretanto, muitas vezes o enfermeiro baseia seus cuidados em evidências frágeis que, frequentemente, não atendem às informações e condutas precisas e cientificamente validadas ${ }^{5}$.

Com os avanços científicos no cuidado ao paciente com feridas, enfermeiros organizaram-se em associações. Em decorrência desse fato, a prática de cuidados a essa clientela tornou-se uma especialidade dentro da enfermagem brasileira, concretizada pela Associação Brasileira de Enfermagem em Dermatologia (SOBEND), Associação Brasileira de Estomaterapia (SOBEST) e Sociedade Brasileira de Enfermagem em Feridas e Estética (SOBENFeF). Contudo, continua sendo um desafio que exige conhecimento específico, habilidades e abordagem que extrapola a esfera biológica.

0 conhecimento do enfermeiro e sua prática fundamentada em evidências científicas iniciam-se durante sua habilitação formal nos cursos de graduação e são fatores primordiais para viabilização e implementação de cuidados tanto para a prevenção como tratamento de feridas. Sendo assim, torna-se sua responsabilidade, juntamente com outros profissionais da saúde, a implementação de tais medidas ${ }^{2-3}$.

A necessidade de conhecimento científico na área de cuidados de pacientes com feridas é destacada por vários autores ${ }^{1-6}$, no sentido da busca da qualidade da assistência, pois é uma área na qual frequentemente a prática é baseada em mitos, tradições e senso comum ${ }^{3}$. Há de se considerar que a rápida evolução de coberturas mudou as práticas de assistência aos pacientes com feridas e deu origem a novas recomendações profissionais ${ }^{3}$.

Nesse sentido, nacionalmente e internacionalmente, vários estudos têm investigado o nível de conhecimento e a situação da prática clínica de profissionais de enfermagem relacionados, especificamente, a úlceras por pressão (UP) no que diz respeito à prevenção e tratamento ${ }^{4-5}$. No Brasil, identificamos escassas pesquisas que abordaram o mesmo tema com profissionais ${ }^{1,3,5} \mathrm{e}$ acadêmicos de enfermagem ${ }^{2,6}$.

Ainda, investigações nacionais sobre a adequação do conhecimento de acadêmicos de enfermagem e de sua experiência clínica durante a graduação, na área de prevenção e tratamento geral de pacientes com feridas, são incipientes ${ }^{6}$.

Um estudo ${ }^{7}$ sugere que cursos de graduação em enfermagem não fornecem uma base de conhecimento adequado no cuidado de pessoas com feridas. Práticas atuais parecem ser influenciadas pela cultura local e ritualismo, em oposição às recomendações de pesquisas baseadas em evidências. Portanto, a busca de conhecimentos dos enfermeiros a respeito do cuidado de pacientes com feridas continua a ser influenciado por interesse específico do tema. Isso pode gerar conflitos constantes de que é o médico 0 responsável pela decisão do tratamento de paciente com feridas ${ }^{7}$. Parece, ainda, não haver consenso sobre qual disciplina clínica deva ser responsável pelos ensinamentos do cuidado de pacientes com feridas ${ }^{7}$. Acredita-se que essa situação pode propiciar uma fragmentação do conhecimento sobre o cuidado a esses pacientes, durante o curso das diversas disciplinas, fato que, futuramente, em sua prática profissional, pode repercutir negativamente na assistência a esses pacientes?.

Partindo do pressuposto do papel fundamental desse futuro enfermeiro no papel gerencial do cuidado, sua atribuição como disseminador e formador de opiniões no cuidado de pacientes com feridas e, ainda, sua responsabilidade no processo de prevenção e tratamento de feridas, justifica-se realizar essa pesquisa.

Diante dessas considerações, o presente estudo teve como objetivo identificar o conhecimento, prática e fontes de informações de graduandos de enfermagem sobre o cuidado de paciente com feridas.

\section{MÉTODOS}

Trata-se de uma pesquisa transversal de caráter descritivo com análise quantitativa de dados, que foram coletados utilizando-se um questionário.

Os dados foram coletados com 68 (85\%) acadêmicos dos 80 (100\%) matriculados em um curso de graduação em Enfermagem de uma Instituição de Ensino Superior Pública do Estado de Mato Grosso do Sul. A coleta, não probabilística intencional, foi realizada em duas turmas ( 40 alunos matriculados em cada turma) em um único dia do mês de outubro dos anos de 2008 e 2009, por constatar-se que nos dias de coleta havia maior número 
de alunos presentes em sala de aula. Para seleção da amostra foram obedecidos os seguintes critérios de inclusão: estar matriculado e cursando o $9^{\circ}$ período do Curso de Graduação em Enfermagem, estar presente no dia proposto para a coleta de dados, aceitar participar do estudo e assinar o Termo de Consentimento Livre e esclarecido.

No período de coleta dos dados, o referido curso abordava o conteúdo de cuidados com portadores de feridas na ementa da disciplina de Fundamentos Técnicos de Enfermagem ofertada no $3^{\circ}$ período do total de oito períodos do curso. A disciplina possuía 68 horas/aulas, sendo 34 horas/ aulas teóricas (duas aulas semanais) e 34 horas/aulas práticas (duas aulas semanais). Além do conteúdo de feridas, a disciplina abordava outros componentes disciplinares referentes às necessidades humanas básicas.

Para atender os objetivos da pesquisa, utilizou-se um instrumento de coleta de dados ${ }^{8}$ que foi traduzido e adaptado para o Português. Após a tradução inicial, realizou-se a retrotradução para o Inglês a fim de verificar se os itens eram similares aos da versão original ${ }^{2}$. Posteriormente foi apreciado, quanto a clareza e compreensão, por três enfermeiros peritos da área de cuidados de pacientes com feridas, sendo dois doutores e um mestre em enfermagem. As sugestões de alteração foram acatadas e a nova versão do instrumento foi aplicada em três acadêmicos que não participaram posteriormente do estudo. Os estudantes não identificaram dificuldades na leitura e no entendimento dos itens. Por fim, o instrumento foi composto de 2 (duas) partes. Na primeira parte, as questões foram referentes aos dados demográficos dos graduandos e às fontes de atualização sobre o tema. A segunda parte abordou informações gerais sobre o conhecimento e prática do graduando de Enfermagem no cuidado de pacientes com feridas, totalizando 19 questões/itens. Como alternativas de respostas, de acordo com o item, o participante tinha a possibilidade de selecionar uma resposta considerando as opções: verdadeiro, falso, sim, não, não sei, às vezes, sempre ou nunca.

0 projeto foi aprovado pelo Comitê de Ética em Pesquisa com Seres Humanos da Universidade Federal de Mato Grosso do Sul e recebeu parecer de aprovação $n^{0}$. 336/2008. A participação na pesquisa foi voluntária, ocorrendo após as orientações, esclarecimentos, autorização e assinatura do Termo de Consentimento Livre Esclarecido.

A coleta de dados ocorreu nos períodos matutino e vespertino, no horário de aulas dos acadêmicos, pois, nos dias de coleta, os alunos tinham reunião com os docentes do estágio supervisionado e, portanto, esperava-se um maior número de alunos presentes. Os questionários foram distribuídos e o pesquisador se ausentou da sala de aula. No final de cada período, o pesquisador retornou a sala e recolheu os questionários. Destaca-se que a coleta foi realizada nos dois períodos a fim de obter maior número de questionários, pois alguns alunos compareceram no período matutino e outros no vespertino, e vice-versa.

0 escore total do teste de conhecimento correspondeu à soma de todas as respostas corretas. Considerou-se com conhecimento adequado sobre 0 tema aqueles que acertassem $80 \%$ ou mais dos itens do teste.

Os dados coletados foram digitados em planilha Excel, para análise no programa Statistical Package for Social Science, versão 19.0 (SPSS). A análise considerou os escores das duas turmas de alunos, e não os escores isolados para cada sujeito. As variáveis relacionadas às características sociodemográficas e educacionais foram sumarizadas e apresentadas descritivamente por meio de distribuição de frequências, valores absolutos e relativos. Em algumas variáveis também foram apresentados os valores médios e os respectivos desvios-padrão. Para análise da verificação de possíveis diferenças entre os escores médios de porcentagem de acertos, no teste de conhecimento, entre os grupos de acadêmicos nos respectivos anos, 2008 e 2009, o teste $t$ de Student, para duas amostras independentes, foi utilizado, considerando um nível de significância de $5 \%$. Assim, foi considerada a diferença entre os grupos se $p$-valor $<0,05$.

\section{RESULTADOS}

Pela escassez de estudos encontrados, tanto nacionais como internacionais, sobre o conhecimento de acadêmicos de enfermagem em relação ao cuidado e prática em âmbito geral de pacientes com feridas, e, ainda, utilizando o instrumento escolhido, consideramos pertinente apresentar os resultados na sequência em que as questões/ itens foram descritas no questionário.

\section{Caracterização dos participantes da pesquisa}

Participaram da pesquisa 68 acadêmicos de enfermagem, sendo $89,7 \%$ do sexo feminino. A idade predominante variou de 21 a 30 anos, com 85,3\%; os maiores de 30 anos representaram 14,7\%. Destaca-se que somente quatro estudantes tinham experiência na área de enfermagem, pois eram técnicos de enfermagem.

\section{Identificação pelos acadêmicos de enfermagem das fontes de informações citadas para atualização no cuidado de feridas.}

Nesta seção, apresentamos as fontes citados pelos acadêmicos para atualização referente ao tema (Tabela 1). 
Tabela 1. Distribuição da frequência das fontes de atualização sobre cuidados com pacientes portadores de feridas citadas pelos acadêmicos de enfermagem. Três Lagoas - MS, 2008-2009.

\begin{tabular}{|c|c|c|c|c|c|c|c|c|}
\hline \multirow[t]{2}{*}{ Fontes de Atualizaçāo } & \multicolumn{2}{|c|}{ Nunca } & \multicolumn{2}{|c|}{ Às vezes } & \multicolumn{2}{|c|}{ Sempre } & \multicolumn{2}{|c|}{ Total } \\
\hline & f & $\%$ & f & $\%$ & f & $\%$ & f & $\%$ \\
\hline Assinatura de periódico (jornais, revista, etc.) & 68 & 100 & & & & & 68 & 100 \\
\hline Leitura independente de artigos cientificos relacionados a feridas & 46 & 67,7 & 15 & 22 & 7 & 10.3 & 68 & 100 \\
\hline Consulta regular à base de dados, sites eletrônicos, etc. & 38 & 55,9 & 16 & 23,5 & 14 & 20,6 & 68 & 100 \\
\hline $\begin{array}{l}\text { Uso da biblioteca para busca de informações e/ou publicações } \\
\text { acerca do assunto }\end{array}$ & 62 & 91,1 & 4 & 5,9 & 2 & 3,0 & 68 & 100 \\
\hline Cursos regulares de extensão universitária & 52 & 76,5 & 12 & 17,6 & 6 & 5,9 & 68 & 100 \\
\hline Grupo de estudos & 63 & 92,6 & 4 & 5,9 & 1 & 1,5 & 68 & 100 \\
\hline Congresso, simpósios, palestra e outros & 61 & 89,7 & 5 & 7,3 & 2 & 3,0 & 68 & 100 \\
\hline Busca de informações com professores & 5 & 7,3 & 27 & 39,8 & 36 & 52,9 & 68 & 100 \\
\hline Busca de informaçōes com outros enfermeiros & 52 & 76,5 & 12 & 17,6 & 4 & 5,9 & 68 & 100 \\
\hline Busca de informações com médicos & 61 & 89,7 & 3 & 4,4 & 4 & 5,9 & 68 & 100 \\
\hline
\end{tabular}

Como se observa na Tabela 1, das dez possibilidades de recursos de atualização que os acadêmicos poderiam utilizar para aperfeiçoar seus conhecimentos no cuidado com portadores de feridas, 9 fontes nunca foram utilizadas pela maioria deles. Destacou-se apenas a busca de informações com professores como um recurso utilizado sempre por $52,9 \%$ dos acadêmicos.

\section{Identificação do conhecimento e prática dos graduandos de enfermagem sobre cuidados com feridas}

A avaliação do conhecimento e prática sobre cuidado de portadores de feridas foi realizada por meio de 19 questões/itens que serão demonstrados a seguir. Inicialmente serão apresentados os itens referentes à prática dos acadêmicos adquiridas em suas experiências práticas durante as aulas e estágios, em seguida, os relacionados ao conhecimento. Esclarecese que a prática dos acadêmicos será apresentada em forma de perguntas e respectivas respostas, devido às diversas modalidades de respostas, o que inviabilizou sua apresentação em tabela.

1. Em seu campo de estágio há normas (protocolo, manual, etc.) acerca do cuidado com feridas?

As respostas foram as seguintes: $\operatorname{sim}, 28 \%$; não, $13,2 \%$; e não souberam da existência de norma, $58,8 \%$.

2. Eu sou capaz de identificar os quatro estágios de úlceras por pressão (UP) nos pacientes que cuido.

Somente $17,6 \%$ se acham capazes de identificar os quatro estágios e $82,4 \%$ referiram não possuírem essa capacidade.

3. Em seu campo de estágio hospitalar, colchões especiais são usados para prevenir úlceras por pressão?
Nesta questão obtiveram-se as seguintes respostas: sim, 30,9\%; não, 7,4\%; e não souberam da existência desse artefato, $61,7 \%$.

4. Em seu campo de estágio as amostras de culturas de feridas são, com maior frequência, obtidas por qual método?

$42,6 \%$ dos pesquisados responderam que a coleta era feita utilizando-se o swab; $57,4 \%$ não souberam.

5. Durante sua prática clínica em campo de estágio, utiliza luvas esterilizadas para realizar curativos de feridas crônicas?

Responderam que sim 32,6\%; e não, $67,4 \%$.

6. Eu sei como aplicar uma bandagem compressiva

Quase a totalidade dos respondentes, 91,2\%, disse que não sabe aplicar uma bandagem compressiva, e apenas $8,8 \%$ responderam que têm essa habilidade.

7. Em sua prática clínica em campo de estágio, a avaliação da pele é par te das atividades que executa a todos os pacientes que cuida?

Constatou-se que a maioria, 51,5\%, não realiza essa atividade, 30,9\% disseram que a realizam, e somente $17,6 \%$ referiram fazê-la às vezes.

8. Recebi informações suficientes sobre feridas crônicas na minha graduação de Enfermagem. A grande maioria, $76,5 \%$, alegou que não recebeu informações suficientes sobre feridas crônicas durante as disciplinas cursadas na graduação até o presente momento da coleta de dados, e somente $23,5 \%$ referiram que receberam conteúdos suficientes.

A Tabela 2 demonstra o conhecimento dos acadêmicos quanto ao cuidado de pacientes portadores de feridas. 
Tabela 2. Distribuição da frequência dos resultados das questões respondidas pelos participantes, no teste de conhecimento, sobre cuidados com portadores de feridas. Três Lagoas-MS, 2008-2009

\begin{tabular}{|c|c|c|c|c|c|c|c|c|}
\hline \multirow[t]{2}{*}{ Questōes } & \multicolumn{2}{|c|}{ Acertos } & \multicolumn{2}{|c|}{ Erros } & \multicolumn{2}{|c|}{ Não sabe } & \multicolumn{2}{|c|}{ Total } \\
\hline & $f$ & $\%$ & $f$ & $\%$ & $f$ & $\%$ & $f$ & $\%$ \\
\hline $\begin{array}{l}\text { 1. Terapia úmida é o "padrão ouro" para tratamento de } \\
\text { feridas crônicas }(V)^{*}\end{array}$ & 36 & 53 & 4 & 5,9 & 28 & 41,1 & 68 & 100 \\
\hline $\begin{array}{l}\text { 2. A dor na ferida deve ser avaliada pelo profissional de } \\
\text { saúde, não pelo paciente }(\mathrm{F})^{* *}\end{array}$ & 38 & 55,8 & 21 & 30,9 & 9 & 13,2 & 68 & 100 \\
\hline $\begin{array}{l}\text { 3. A avaliação da ferida é um processo cumulativo que } \\
\text { compreende a observação, coleta de dados e evolução (V) }\end{array}$ & 68 & 100 & & & & & 68 & 100 \\
\hline $\begin{array}{l}\text { 4. A escala de Braden é um instrumento usado para avaliar } \\
\text { o risco do paciente desenvolver úlcera vascular }(F)\end{array}$ & 8 & 11,8 & 16 & 23,5 & 44 & 64,7 & 68 & 100 \\
\hline $\begin{array}{l}\text { 5. Os sinais clássicos de infecção (dor, calor, rubor, edema, } \\
\text { pus) podem não estar presentes em pacientes com feridas } \\
\text { crônicas ou naqueles que estão imunossuprimidos (V) }\end{array}$ & 29 & 42,6 & 36 & 53 & 3 & 4,4 & 68 & 100 \\
\hline $\begin{array}{l}\text { 6. Em feridas crônicas, a única bactéria boa é aquela que está } \\
\text { morta (F) }\end{array}$ & 9 & 13,2 & 37 & 54,4 & 22 & 32,4 & 68 & 100 \\
\hline $\begin{array}{l}\text { 7. A seleção da cobertura da ferida deve ser baseada na } \\
\text { característica do seu leito (umidade, drenagem ou presença de } \\
\text { tecido desvitalizado) (V) }\end{array}$ & 68 & 100 & & & & & 68 & 100 \\
\hline $\begin{array}{l}\text { 8. O primeiro estágio da úlcera por pressão é facilmente } \\
\text { identificado nas pessoas de pele escura/negra }(F)\end{array}$ & 41 & 60,3 & 6 & 8,8 & 21 & 30,9 & 68 & 100 \\
\hline $\begin{array}{l}\text { 9. Enzimas (papaina, colagenase, etc.) são eficazes na remoção } \\
\text { de tecido desvitalizado das feridas crônicas ( } V \text { ) }\end{array}$ & 23 & 33,8 & 11 & 16,2 & 50 & 34 & 68 & 100 \\
\hline 10. PVPI é indicado para limpar feridas crônicas (F) & 40 & 58,8 & 23 & 33,8 & 5 & 7,4 & 68 & 100 \\
\hline $\begin{array}{l}\text { 11. Coberturas de gazes úmidas para seca são mais indicadas no } \\
\text { tratamento de feridas crônicas limpas e com tecido de granulação } \\
\text { (F) }\end{array}$ & 5 & 3,4 & 21 & 31 & 42 & 62 & 68 & 100 \\
\hline
\end{tabular}

\section{DISCUSSÃO}

Este estudo nos revelou conhecimentos importantes sobre o tema investigado e cada questão será discutida, individualmente, de acordo com a sequência que foi questionada aos acadêmicos.

Em relação às fontes de informação para atualização do assunto, 52,9\% dos acadêmicos referiram sempre buscar informações com professores, apenas 17 (25\%) obtiveram maior número de acertos dos itens de conhecimento.

0 tratamento do portador de ferida é dinâmico e deve acompanhar a evolução científica e tecnológica. Os protocolos auxiliam na abordagem do usuário, na indicação do tratamento e na avaliação no decorrer da cicatrização. 0 protocolo, além de instrumentalizar os profissionais quanto aos cuidados e sistematizar a assistência a ser prestada ao portador de ferida, fornecerá subsídios para implementação do tratamento e padronizações das coberturas utilizadas". Os resultados deixam claro que a maioria desconhece a existência desses guias em seus campos de atuação acadêmica.

Constata-se que os acadêmicos não estão preparados para iniciar o tratamento de (UP). 0 adequado estadiamento das úlceras é parte da avaliação dessa lesão, sendo importante para planejar o tratamento. Em 2007, o National Pressure Ulcer Advisory Panel (NPUAP) apresentou a nova definição da UP e os estágios, pois as descrições originais do NPUAP não eram muito claras para os profissionais e levavam, muitas vezes, à classificação inadequada devido à dermatite perineal e/ou a lesão tissular profunda ${ }^{9}$. Destaca-se que essa agência atribui ao enfermeiro a habilidade de estadiar as úlceras por pressão como uma de suas competências básicas. Portanto, há de se considerar investimentos no ensino dessa temática, ainda nos cursos de graduação.

Quando disponíveis, colchões especiais poderiam ser utilizados para ajudar a manter a integridade da pele e prevenir UP em pacientes de alto risco. Quem necessita permanecer longo tempo acamado pode usar colchões especiais, e, para os pacientes que já apresentam UP, em diferentes partes do corpo, o uso de colchões de ar ou de espumas especiais como visco elástico podem diminuir a pressão e proporcionar alívio desde que tenham densidade adequada ${ }^{10}$. Entretanto, não existem estudos nacionais que avaliaram a sua capacidade de diminuir a pressão interface ou em reduzir a incidência de UP3.

Destaca-se que a maioria $(61,7 \%)$ dos acadêmicos não soube informar a disponibilidade de colchões para prevenção de úlceras por pressão nos setores que passaram durante suas atividades clínicas.

Em relação aos métodos de coleta de material microbiológico de feridas, os acadêmicos tinham quatro opções de escolha nesta questão: swab, biópsia, aspiração e "não sei". No entanto, só assinalaram a opção swabe "não sei". Observase que a maioria desconhece o método utilizado para cultura de feridas nos campos clínicos que desenvolveram suas 
atividade clínicas. No entanto, não se exclui a possibilidade da falta de oportunidade de realizar ou observar a coleta de material microbiológico de feridas durante sua permanência nos campos de prática clínica, fato que pode ter influenciado as respostas quanto a essa questão.

A biópsia de tecido é tida como "padrão ouro" para se obter amostra de culturas em feridas, uma vez que identifica os microrganismos que infectam o tecido. Entretanto, este método não está disponível em todos os estabelecimentos de saúde ${ }^{11}$.

A cultura por swab é utilizada universalmente, devido ao fato de não ser invasiva, não onerosa e de fácil execução. Mas os resultados podem indicar apenas a colonização da ferida, pois as amostras nem sempre são obtidas corretamente. Para melhores resultados, indicase a limpeza do leito da ferida antes de coletar o swab, no intuito de remover os microrganismos da superfície, e também coletar a amostra rodando o swab em $360^{\circ}$, pressionando-o sobre uma área de $1 \mathrm{~cm}^{2}$ por cinco segundos ${ }^{11}$.

0 uso de luvas não estéreis para trocar curativos de uma ferida crônica é conduta aceitável. Luvas esterilizadas são requeridas para procedimentos cirúrgicos e contato com topografias estéreis do corpo ${ }^{11}$. Princípios assépticos, ou seja, a aplicação de medidas de prevenção contra contaminação, são importantes para o controle de infecção, independente do uso de luvas estéreis ou não $0^{12}$. Considerando que todas as feridas são colonizadas e que as luvas de procedimento possuem densidade bacteriana reduzida, estas podem ser utilizadas para realização de curativos ${ }^{11,12}$. A maioria dos alunos referiu que não utilizam luvas esterilizadas para trocar curativos de feridas crônicas.

Bandagem compressiva graduadas da região distal do pé ao joelho são padrões de tratamento para úlceras vasculares em ausência de doença arterial significativa. Enfermeiros deveriam ser treinados sobre cuidados com úlceras venosas nas pernas, incluindo a avaliação do paciente e aplicação de bandagem compressiva ${ }^{13}$. A maioria refere não possuir habilidades na aplicação de bandagens, provavelmente devido a falta de experiência e contato com este material tanto durante o curso quanto no campo de atividades práticas, pois trata-se de insumo oneroso e pouco comum nos estabelecimentos de assistência à saúde.

A avaliação da pele deveria ser executada e documentada diariamente em todos os pacientes. A avaliação regular da pele permite a detecção e tratamento precoce de úlceras por pressão, fissuras na pele e outros problemas dermatológicos. Esta é uma importante função do enfermeiro; então, cautela precisa ser tomada em delegar essa atividade para pessoas que não estão habilitadas para tal função, ${ }^{8}$ como, por exemplo, a equipe técnica de enfermagem. Ademais, há de se considerar as limitações dos acadêmicos de enfermagem em tomar decisões quanto ao cuidado aos pacientes com feridas, pois geralmente essa prerrogativa é de competência do médico assistente ou enfermeiro da unidade, ou, ainda, das comissões responsáveis pelos cuidados de pacientes com feridas.

Ao serem questionados se receberam instrução suficiente sobre feridas crônicas na graduação de enfermagem, os entrevistados tinham a oportunidade de realizar comentários sobre o tópico, e $39(57,4 \%)$ relataram que durante o curso praticamente só tiveram um período de aproximadamente 4 horas teóricas e 2 horas práticas em laboratório que versava especificamente sobre cuidado com pacientes portadores de feridas; foi relatado, ainda, que nem a instituição de ensino nem outras instituições na cidade ofereciam cursos, palestras ou outros eventos sobre o assunto.

No entanto, algumas questões emergem quando se considera o nível de preparação reportado pelos acadêmicos: 0 que seria educação suficiente sobre o tema? A percepção dos acadêmicos em relação ao seu nível de preparação é influenciada pelo seu campo de atividades práticas? Ou eles se tornam mais conscientes de suas limitações técnico-científicas quando entram em contato com as experiências clínicas?

A seguir, discutiremos as questões referentes ao conhecimento dos acadêmicos sobre cuidado com portadores de feridas.

Desde a década de 1960 do século XX, foi demonstrado que manter o leito da ferida úmido é condição fundamental para a aceleração da epitelização, aumentando esse processo em cerca de 2 a 3 vezes quando comparado com o leito seco. Este conceito revolucionou a prática do tratamento de ferida crônica. Dessa forma, o objetivo do profissional de saúde ao tratar uma ferida é mantê-la em ambiente úmido controlado ${ }^{13}$. Constatou-se que os pesquisados, na sua maioria, conhecem 0 princípio. No entanto, destaca-se o déficit de conhecimento neste tópico uma vez que, $37,2 \%$ não acreditam ou desconhecem o conceito.

A dor é uma experiência comum e subjetiva enfrentada por pacientes com feridas, principalmente as crônicas. Assim, 0 autorrelato de dor é o mais confiável indicador de sua presença em caso de ferida. Portanto, esse sinal deve ser reportado pelo paciente, não pelo profissional de saúde. Por ser uma experiência subjetiva, a dor não pode ser objetivamente determinada por instrumentos, e sim ser mensurada em sua característica e intensidade pelo relato do paciente. A mensuração da dor é extremamente impor tante no ambiente clínico, então o que o paciente descreve é mais fidedigno do que qualquer um diz ou julga ${ }^{14}$. A maioria dos entrevistados respondeu corretamente, mas ainda há déficit de conhecimento nesta área, pois para $44,1 \%$ dos acadêmicos esse tópico ainda não está claro.

As feridas devem ser avaliadas por meio de processo contínuo e cumulativo, pois são dinâmicas e mudam conforme cicatrizam. A natureza holística da avaliação de portadores de feridas requer observar as condições globais, assim como 
muitas características das feridas. Para tanto é necessária visão clínica que relacione alguns pontos importantes que influenciam neste processo, como: controle da patologia de base, aspectos nutricionais, emocionais, infecção, medicamentos, imobilidade e cuidado educativo associado à cober tura ${ }^{1}$. Nesta questão, foi unânime 0 entendimento dos entrevistados quanto a este processo continuado.

A ferramenta de avaliação de risco Escala de Braden foi desenvolvida para identificar aqueles que têm risco de desenvolver UP e não úlceras vasculares. Essa escala já foi adaptada e validada para 0 Brasi $^{15}$. A escala possui seis subescalas que refletem os determinantes críticos de pressão (mobilidade, atividade e percepção sensorial) e fatores que influenciam na tolerância da pele à pressão (umidade da pele, estado nutricional, friç̧ão e cisalhamento). É notório o desconhecimento por parte dos respondentes do propósito da Escala de Braden, pois apenas 11,8\% reconheceram 0 verdadeiro objetivo da escala.

Em relação ao instrumento anteriormente descrito, cabe ressaltar que na instituição não estava implantada essa Escala na época da coleta de dados, fato que pode ter influenciado os resultados desfavoráveis.

A maioria dos entrevistados acredita que os sinais e sintomas clássicos de infecção - rubor, calor, edema, dor e exsudato purulento - estão presentes em pacientes com feridas crônicas ou naqueles que estão imunossuprimidos. Nos casos de feridas crônicas com longo curso de tratamento, acredita-se que o mecanismo de inflamação pode ser diminuído devido à presença de biofilme que inibe a resposta imunológica local da ferida, assim não desencadeando os sinais clássicos de infecçãa $0^{16-17}$.

Toda ferida crônica possui bactérias em seu leito, sendo que algumas podem ser benéficas, pois impedem que outras com maior virulência se estabeleçam na ferida. Portanto, o que determinará se uma ferida se tornará infectada dependerá principalmente da resistência imunológica do indivíduo, da densidade microbiana e sua virulência ${ }^{12,16-17}$. Constatou-se que $54,4 \%$ dos respondentes acreditam que a ferida crônica não deve possuir bactérias, demonstrando que não compreendem as relações microbiológicas que se estabelecem nesse tipo de ferida.

Em relação à seleção da cobertura da ferida, há de se considerar que todas são distintas umas das outras, e a escolha de uma cobertura deve ser direcionada por características particulares a cada ferida; por exemplo, tecido desvitalizado versustecido viável, infectado versusnão infectado, quantidade de exsudato, dor, dentre outros. Também é necessário lembrar que feridas, durante o processo de cicatrização, mudam suas características, necessitando de novas condutas, inclusive a escolha da cobertura ${ }^{1}$. Todos acertaram essa afirmativa mostrando consenso entre os acadêmicos.

A literatura contém pouca informação sobre a identificação do primeiro estágio da UP em pessoas com pigmentação escura da pele ou negras. A falha dos profissionais em identificar em peles negras úlcera por pressão no estágio I é uma das prováveis explicações que demonstram por que esses pacientes têm mais úlceras de estágio II do que estágio I. A pele de cor negra pode não apresentar esbranquecimento visível e sua cor pode diferir da pele ao redor ${ }^{8-9} 0$ s acadêmicos, na maioria, discordaram da afirmação.

Em relação às enzimas, estas vêm sendo usadas para desbridar feridas por mais de 40 anos. Este método passa fundamentalmente pela aplicação tópica de enzimas proteolíticas ou exógenas no leito da ferida, que degradam o tecido necrótico/desvitalizado e podem ser combinadas eficazmente com a cicatrização em ambiente úmido ${ }^{17}$. Mesmo sendo utilizadas há décadas, e na instituição possuir a papaína e colagenase para o tratamento de feridas, a maioria dos acadêmicos desconhece a verdadeira finalidade das enzimas, mostrando que apenas 33,8\% conhecem a eficácia dessa modalidade terapêutica.

Durante séculos o iodo foi o antisséptico mais utilizado para limpar e tratar feridas. Embora o polivinilpirrolidona-iodo tenha sido usado amplamente para limpar feridas, atualmente recomendam-se produtos não citotóxicos ${ }^{18}$. Diferentes antibióticos podem matar bactérias seletivamente sem prejudicar o tecido saudável, polivinilpirrolidona-iodo e outros antissépticos tópicos prejudicam as células vitais e reduzem insignificantemente as bactérias do leito da ferida. Ainda que iodóforos (carregador de iodo) apresentem alguns resultados positivos na cicatrização de feridas e prevenção de infecção, ${ }^{18}$ seu uso para limpeza de feridas não está indicado ${ }^{8}$. A maior parte dos acadêmicos, $58,8 \%$, reconhece que o produto é inadequado para limpeza de feridas crônicas; no entanto, 33,8\% acreditam que o produto deva ser utilizado para esse fim, e $7,4 \%$ não souberam responder.

Cobertura úmida para seca pode ser usada como um tipo de desbridamento mecânico em feridas com tecido necrótico, mas deve-se evitá-la em feridas limpas com tecido de granulação. Além de não manter um ambiente de cicatrização úmido, esse tipo de cobertua adere ao leito da ferida conforme ocorre evaporação, assim, ao removê-la, lesiona-se o tecido de granulação. Alguns acadêmicos podem ter confundido úmida para seca com molhada para úmida, explicando a falta de consenso nessa questão. Coberturas molhadas para úmida são coberturas de gaze umedecidas com solução salina que não devem secar entre as trocas. Como a cobertura está sempre úmida, ela propicia um meio ideal à cicatrização. Em contraste, uma cobertura úmida para seca adere ao leito da ferida, e, ao removê-la, ocasiona-se um desbridamento mecânico na feridå . Cabe destacar que essa nomenclatura para definir esses tipos de coberturas é pouco disseminada no Brasil.

Das 11 questões/itens referentes ao conhecimento sobre cuidado com feridas, somente $6(54,5 \%)$ itens alcançaram acertos acima de 50\%. Desses, $4(36,3 \%)$ não chegaram a $70 \%$ de acertos. Apenas $2(11,1 \%)$ itens foram respondidos 
corretamente por todos os acadêmicos, e nas três questões que avaliaram o conhecimento do acadêmico em relação aos dispositivos ou materiais disponíveis no campo de atividade de prática clínica para o cuidado de feridas, a maioria desconhecia os itens avaliados.

Considerando os resultados globais do teste de conhecimento, os acadêmicos de enfermagem das turmas de 2008 e 2009 obtiveram, em média, 56,3\% ( $d p=7,6 \%$ ) e $57,9 \%$ ( $d p=8,2 \%$ ) de acertos, respectivamente. 0 teste $t$ de Student não mostrou diferença estatisticamente significante $(p<0,82)$ entre as turmas. Pode-se inferir que a equidade entre os escores totais de conhecimento das turmas foi devida ao fato de o conteúdo ser administrado com a mesma carga horária, conforme relatado por alguns acadêmicos na questão aberta.

Acreditamos, como docentes e enfermeiros da assistência, que o conteúdo sobre cuidado de pacientes com feridas no presente curso é insuficiente diante da complexidade da temática, o que pode ter influenciado os resultados ora apresentados.

Esse estudo apresenta algumas limitações: a amostra foi pequena e apenas alunos de uma mesma instituição foram pesquisados, e em anos diferentes, o que pode ter possibilitado a troca de informações entre eles. 0 estudo necessita ser replicado, após refinamento do instrumento, com uma amostra maior e em instituições diversas tanto de nível público quanto privado, para que se tenha um panorama de como o tema está sendo ofertado e assimilado pelos acadêmicos. Ressalta-se que uma das prerrogativas do enfermeiro no Brasil é supervisionar e orientar as ações do pessoal de nível técnico de enfermagem. Assim, a deficiência de conhecimento no cuidado de pacientes com feridas poderá influenciar sua prática, bem como induzir a dos outros membros da equipe de enfermagem ${ }^{3}$.

\section{CONCLUSÃO}

Os resultados obtidos nesta pesquisa permitiram identificar os aspectos do cuidado de pacientes com feridas que os acadêmicos de enfermagem conhecem adequadamente e aqueles que necessitam de atualização para um desempenho baseado em evidências e, consequentemente, um cuidado de qualidade.

Constatou-se que a porcentagem média de acertos no teste de conhecimento para ambas as turmas de alunos mostrou déficits de conhecimento referentes ao tema.

Os resultados deste estudo apontam que investimentos sobre o tema, iniciando-se na carga horária da disciplina dedicada ao ensino do cuidado de pacientes com feridas, precisam ser repensados no colegiado do referido curso, além da necessidade de estimular os acadêmicos a buscarem fontes de atualização diversas, haja vista que a maioria não as utiliza. Esse fato é preocupante, principalmente considerando que o mercado lança novas tecnologias e pesquisas vêm direcionando e redirecionando o cuidado com feridas constantemente.
Por fim, considera-se que a avaliação apresentada quanto à prática e ao conhecimento dos estudantes seja importante para o próprio curso de graduação, que pode rever e repensar seu projeto político-pedagógico, estrutura curricular, entre outros. Assim, discussões desses conteúdos nas diversas disciplinas da graduação do referido curso, ou mesmo a criação de uma disciplina curricular que contemple essa temática de modo a abarcar os diversos aspectos envolvidos no processo de cuidar de pacientes com feridas, parecem ser relevantes.

\section{REFERÊNCIAS}

1. Oliveira BGRB; Rodrigues ALS. Cicatrização de feridas cirúrgicas e crônicas: um atendimento ambulatorial de enfermagem. Esc. Anna Nery Rev. Enferm. 2003 abr; 7(1): 104-13.

2. Caliri MHL; Miyazaki MY; Piper B. Knowledge about pressure ulcers by undergraduate nursing students in Brazil. Ostomy Wound Manage. 2003 mar; 49(3): 54-63.

3. Rangel EML, Caliri MHL. Práticas de enfermagem de um hospital geral sobre a prevenção da úlcera de pressão. Rev. paul. enferm. 2006 abr/jun; 25(2): 96-101.

4. Pancorbo HPL; Garcia FFP; Lopez MIM; Lopez OJ. Pressure ulcer care in Spain: nurses' knowledge and clinical practice. J. adv. nurs. 2007 may; 58(4): 327-38.

5. Miyazaki MY, Caliri MHL, Santos CB. Conhecimento dos profissionais de enfermagem sobre prevenção da úlcera por pressão. Rev. Latino-Am. Enfermagem [Internet]. nov-dez 2010 [acesso em: 27 set 2011]; 18(6): [10 telas]. Disponivel em: <http://www.scielo.br/pdf/rlae/v18n6/ pt_22.pdf $>$.

6. Santos AAR; Medeiros ABA; Soares MJGO; Costa MML. Avaliação e tratamento de feridas: o conhecimento de acadêmicos de enfermagem. Rev. enferm. UERJ. 2010 out/dez; 18(4): 547-52.

7.Ashton J; Price P. Survey comparing clinicians' wound healing knowledge and practice. Br. j. nurs. 2006 oct./nov.; 15(19): S18-S26

8.Ayello EA; Baranoski S; Salati DS. Nursing 2005 wound care survey report. Nursing (Springhouse). 2005 jun.; 35(6): 36-45.Parte inferior do formulário

9. Santos VLCG; Caliri MHL. (Trads.). Conceito e classificação de úlcera por pressão: atualização do NPUAP. Revista Estima. 2007 jul/ago/set; 5(3): 43-4.

10. Trueman P; Whitehead SJ. The economics of pressure relieving surfaces: an illustrative case study of the impact of high-specification surfaces on hospital finances. Int Wound J. 2010 feb.; 7: 48-54. 
11. Gardner SE; Frantz CL; Saltzman RA; Hillis SL; Park H; Scherubel M. Diagnostic validity of three swab techniques for identifying chronic wound infection. Wound Repair Regen. 2006 sep./oct.; 14: 548-57.

12. Ferreira AM, Andrade D. Avaliação microbiológica de luvas de procedimento: considerações para seu uso na técnica de curativo. 2010 abr/jun; Rev. enferm. UERJ.2010; 18(2): 191-7.

13. Winter GD. Formation of the scab and rate of epithelization of superficial wounds in the skin of the young domestic pig. Nature. 1962 jan.; 193: 293-4.

14. Woo KY; Sibbald RG; Fogh K; Glynn C; Krasner D; Leaper D. Assessment and management of persistent (chronic) and total wound pain. Int Wound J. 2008 jun; 5: 205-15.

15. Paranhos WY, Santos VLCG. Avaliação de risco para úlceras de pressão por meio da Escala de Braden, na língua portuguesa. Rev. Esc. Enferm. USP. 1999; 33(Esp): 191-206.

16. Bjarnsholt T; Kirketerp-Moller K; Jensen PO; Madsen KG; Phipps R; Krogfelt K. Why chronic wounds will not heal: a novel hypothesis. Wound Repair Regen. 2008 jan/feb; 16: 2-10.

17. Ayello EA; Cuddigan JE. Conquer chronic wounds with wound bed preparation. Nurse Pract. 2004 mar.; 29(3): 8-25.

18. Oliveira AS, Santos VLCG. Uso de iodóforo tópico em feridas crônicas: revisão da literatura. Rev. Latino-Am. Enfermagem. 2007 jul./aug.; 15(4): 671-6. 